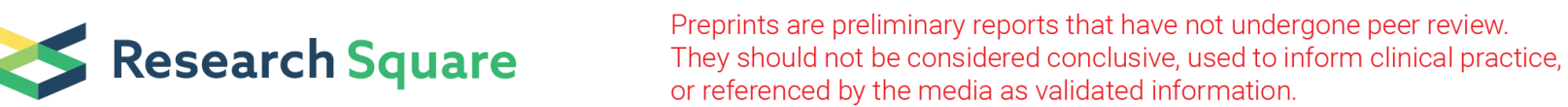

\section{The Continuation of Traditional Birth Attendances in the Remote Rural Communities without any Training and the Problem of Integration with Health Facilities in West Omo Zone 2021: Exploratory Qualitative Study}

Alemnew Wale ( $\square$ walealemnew@gmail.com )

Mizan Tepi University

Aychew Kassie

Mizan Tepi University

Desalegn Girma

Mizan Tepi University

Hailemariam Amsalu

Mizan Tepi University

Mastewal yechale

Mizan Tepi University

\section{Research Article}

Keywords: Role, Traditional, Birth, Attendance, Remote, West Omo, Ethiopia, 2021

Posted Date: August 11th, 2021

DOI: https://doi.org/10.21203/rs.3.rs-770231/v1

License: (c) (1) This work is licensed under a Creative Commons Attribution 4.0 International License.

Read Full License 


\section{Abstract}

Introduction: Mothers in the rural community of Ethiopia prefer to give birth at home because most TBAs do not charge anything for deliveries and are willing to make house visits, which allow the mother privacy that many prefer. The shift toward training TBAs in developing countries, specifically those in SubSaharan Africa, is an important intervention that health care workers can utilize to increase the health of both mothers and children, so Assessing the role of traditional birth attendance in Feto-maternal care during pregnancy, childbirth, postnatal period and integration with health professionals in West Omo Zone will a great role for bringing out the endogenous experience to the scientific standards.

Objective: To explore the role of traditional birth attendance in Feto-maternal care during pregnancy, childbirth, postnatal period, and integration with health professionals in West Omo Zone.

Methods: A qualitative study will be employed by using individual in-depth interviews, focus group discussion, and key informant interviews. The individual in-depth interview and focus group discussion will be tape-recorded after verbal consent will be granted and finally translated and transcribed by the data collectors. Thematic analysis will be used to analyze the qualitative data based on emerging themes and sub-themes in line with the study objectives.

Result: A total of 34 individuals such as 2 FGD (9 each group),6 in-depth interviews, 10 key informants were used. The role of TBAs in remote areas of Ethiopia is very vital to save the life of women and the Childs. TBAs take care of the women during pregnancy labor and delivery as well in the postpartum period but with no formal integration with health facility and training.

Conclusion: Locally demotion and punishment of the TBA, lack of formal relationship between TBAs and the health facility resulted in increasing Fetomaternal morbidity and mortality especially in remote areas of the country. Even if the traditional birth attendants always on the side of the women in the previous year currently they forced to stop their activity because of prohibited by the local judge and no motivation and training to improve the performance of TBA to trained traditional birth attendance.

\section{Introduction}

According to World Health organization of 2015 , about $99 \%$ of maternal death occurs in developing countries, from this half them were in sub-Saharan Africa. As WHO indicates that A successful strategy to reduce the global maternal mortality rate has to be increasing the number of trained and educated individuals for helping and caring for the mother during pregnancy, delivery, and postnatal period ${ }^{11,12}$.

The integration of traditional birth attendance with the country health service, particularly in the field of maternal and child health and family planning very helps full in developing countries. Several expert committees of the world health organization referred the maternity care in connection with the trained traditional birth attendance workers starting as early as 1952 to $1955^{10}$. 
One advantage that TBA utilization offers is that TBAs are already connected to the communities they serve. These women, while untrained and uneducated in the standards set by the formal health care system, have already established a trusting relationship with women in need of a birth attendant ${ }^{1}$.

Much of the logistical problems associated with SBAs, like lack of travel or transportation, expensive transportation services, and blow poverty line and difficult geographic area are overcome by TBAs already being incorporated into their communities. In rural parts of Africa, 60 to $90 \%$ of pregnant women are using TBAs during their deliveries. If these TBAs could be taught rather than replaced, then the formal health care system would not need to exert time, money, and strategy in getting TBAs into these underserved places ${ }^{2}$. Close to community maternal health providers play an important role in bridging communities and health systems and their role in maternal health are particularly very vital for rural community ${ }^{5,6}$.

Trained traditional birth attendants remain Vital for the rural community in need of maternal and child health care services and with close supportive supervision and evaluation of the training, the TBAs can

greatly contribute to decreasing maternal and newborn mortality rates ${ }^{4,9}$. Having such great full role and service of the traditional birth attendants to the rural community, as our knowledge is concerned studies are very limited in the country as well no study in the study area, So this study, exploring the role of traditional birth attendance inFeto-maternal care during pregnancy, childbirth, postnatal period and integration with health professionals in West Omo Zone, will bring out the endogenous skill and experience of TBA to the standards of health professional activities and enforce them to get training as well integrate with health facility to work out the rural community concern regarding Feto -maternal care to together with skill birth attendance.

\section{Methods}

\section{Study design and setting}

A qualitative study design was conducted in West Omo Zone with the use of focus group discussion, indepth interviews, and key informant interviews for data collection. In this study 6 in-depth interviews, 2 focus group discussions (every 9 individuals), and 10 key informants with a diversity of TBA, women, men, midwives and health extension workers, community and religious leaders were included. West Omo Zone is a newly established zone of south nation nationalities and peoples of the Ethiopian region.

\section{Source and study population}

All TBAs, health professionals, women, men community and religious leaders residing in West Omo Zone were the source population, and all purposively selected traditional birth attendants, women, men, community and religious leader, and health professionals in the selected area were the study population. 
Currently, not participants in the birth process and the participants in absence of translators and severe ills were excluded from the study.

\section{Sample size}

The sample size will be determined by relative data saturation; But a minimum of 6 in-depth interviews and 2FGD (9 each FGD) and 10 key informants, a total of 34 individuals were utilized.

\section{Procedures}

TBAs, men, women, health professionals, religious and community leaders will be recruited into the study after they individually asked for consent to participate in the study. The purpose of the study and all the required procedure was explained for each study participants

The data collector will be recruited based on their academic qualification and experience in qualitative data collection. The team comprised of public health, social science, midwifery, and health extension worker. There were a total of 4 data collectors, 2 Coordinators from the local area. Open-ended interview guideline was prepared for focus group discussion, key informants and individual in-depth interview. The individual in-depth interview, key informants and focus group discussion will be tape-recorded after verbal consent will be granted and finally translated by the data collectors. The community, religious leader, and health profession were the part of key informants. They were selected based on the richness of information.

\section{Data quality control}

The data quality was ensured throughout the research process by giving 4-day duration training for the data collector, coordinators, and translator regarding the whole interview guides and how to approach the respondents. Daily supervision and checkup of the data and pretest was done in the nearby area of the study area and trustworthiness for this study was ensured by the following

Credibility: The data collectors and facilitators will spend enough time with participants to explain the process of data collection to the participants and use multiple data source or collection techniques (audio recording, note-taking, and observation). Peer debriefing and member checking will be applied as much as possible.

Dependability: The investigator will try to provide a detailed description of the process used

like the selection of study participants, the process of data collection procedure, duration of the interview, method of data analysis, and the results and interpretations will be supported by data and existing literature. 
Transferability: The investigator will try to provide a detailed or thick description of the study

finding and compare the study finding with existing literature.

Conformability: detail of data collection and analysis (audit trail) will be maintained so that the investigator will be kept interview record in a safe place

\section{Data analysis and interpretation}

Before data analysis, audio records will be listed several times transcribed verbatim into Amharic and then translated into the English language for analysis. Each transcript read line by line on several occasions while playing the audio record as it enables to check transcription error and greater familiarity with the data. The transcripts will be imported to Atlas. ti version 8 software. Thematic analysis will be used to analyze the qualitative data based on emerging themes and sub-themes in line with the study objectives. The analysis will be conducted using the thematic analysis approach. This includes; data familiarization, coding, identifying themes, defining themes, analysis, and interpretation of data across the themes. The researchers will design an initial codebook, which will be accepted by all researchers

\section{Result And Discussion}

A total of 34 individuals such as 2 FGD(9 each group),6 in-depth interviews, 10 key informants with a diversity of midwives, health extension workers, community and religious leaders for key informants, women, and men for FGD, and TBA for in in-depth interview were asked. Except for the community and religious leader, most of the participants were below the age range of 40 years old. For more detail see (table-1). The finding from the qualitative part of was presented by two main themes and several subthemes emerged with the main theme for more detail see (figure-1)

Table 1

Socio demographic characteristics of the respondents in West Omo Zone in 2021 


\begin{tabular}{|c|c|c|c|c|c|}
\hline \multicolumn{2}{|c|}{$\begin{array}{l}\text { Socio demographic } \\
\text { Variables }\end{array}$} & \multicolumn{2}{|c|}{ Key informants $N=10$} & \multirow{2}{*}{$\begin{array}{l}\text { In-depth } \\
\text { interview }\end{array}$} & \multirow{2}{*}{$\begin{array}{l}\text { Focus group } \\
\text { discussion } \\
\text { Women and } \\
\text { men }(n=18)\end{array}$} \\
\hline & & $\begin{array}{l}\text { Midwives and } \\
\operatorname{HEW}(n=6)\end{array}$ & $\begin{array}{l}\text { Religious and } \\
\text { community } \\
\text { leader( } n=4)\end{array}$ & & \\
\hline \multirow[t]{3}{*}{ Age } & $\begin{array}{l}\text { Below } 40 \\
\text { years }\end{array}$ & $4(66.6 \%)$ & $1(25 \%)$ & $4(66.6 \%)$ & 14(77.8\%) \\
\hline & $\begin{array}{l}40 \text { and } \\
\text { above }\end{array}$ & $2(33.3 \%)$ & $3(75 \%)$ & $2(33.3 \%)$ & $4(22.2 \%)$ \\
\hline & Total & $6(100 \%)$ & $4(100 \%)$ & $6(100 \%)$ & $18(100 \%)$ \\
\hline \multirow[t]{3}{*}{ Sex } & Female & $5(83.3 \%)$ & $0(0 \%)$ & $6(100 \%)$ & $9(50 \%)$ \\
\hline & Male & $1(16.6 \%)$ & $4(100 \%)$ & $0(0 \%)$ & $9(50 \%)$ \\
\hline & Total & $6(100 \%)$ & $4(100 \%)$ & $6(100 \%)$ & $18(100 \%)$ \\
\hline \multirow{3}{*}{$\begin{array}{l}\text { Marital } \\
\text { status }\end{array}$} & Single & $2(33.3 \%)$ & $1(25 \%)$ & $2(33.3 \%)$ & $5(27.8 \%)$ \\
\hline & Married & $4(66.6 \%)$ & $3(75 \%)$ & $4(66.6 \%)$ & $13(72.2 \%)$ \\
\hline & Total & $6(100 \%)$ & $4(100 \%)$ & $6(100 \%)$ & $18(100 \%)$ \\
\hline \multirow[t]{3}{*}{ Religious } & Orthodox & $3(50 \%)$ & $2(50 \%)$ & $2(33.3 \%)$ & $12(66.6 \%)$ \\
\hline & Protestant & $3(50 \%)$ & $2(50 \%)$ & $4(66.6 \%)$ & 6(33.3\%) \\
\hline & Total & $6(100 \%)$ & $4(100 \%)$ & $6(100 \%)$ & $18(100 \%)$ \\
\hline \multirow[t]{3}{*}{ Education } & $\begin{array}{l}\text { Informal } \\
\text { education }\end{array}$ & $0(0 \%)$ & $4(100 \%)$ & $6(100 \%)$ & 16(88.9\%) \\
\hline & $\begin{array}{l}\text { Formal } \\
\text { education }\end{array}$ & $6(100 \%)$ & $0(0 \%)$ & $0(0 \%)$ & $2(11.1 \%)$ \\
\hline & Total & $6(100 \%)$ & $4(100 \%)$ & $6(100 \%)$ & $18(100 \%)$ \\
\hline \multirow[t]{4}{*}{ Occupation } & House wives & $0(0 \%)$ & $0(0 \%)$ & $6(100 \%)$ & $9(50 \%)$ \\
\hline & Farmer & $0(0 \%)$ & $4(100 \%)$ & $0(0 \%)$ & $9(50 \%)$ \\
\hline & $\begin{array}{l}\text { Government } \\
\text { employee }\end{array}$ & $6(100 \%)$ & $0(0 \%)$ & $0(0 \%)$ & $0(0 \%)$ \\
\hline & Total & $6(100 \%)$ & $4(100 \%)$ & $6(100 \%)$ & $18(100 \%)$ \\
\hline
\end{tabular}




\section{Theme 1 continuation of TBA in their activities}

\section{Sub-theme 1.1 maternal care during pregnancy}

TBA in our locality acts as a health professional to detect the presentation of the fetus. They simply observe the abdomen of the women to guess the presentation of the fetus (explained by 34 years old pregnant women). As TBA I revisit the pregnant women for the care of nausea and vomiting and I had locally produced roots for relieving nausea and vomiting (40 years with 20 years of experience in TBA).TBA was always on the side of the women even if the women is not pregnant and fail to conceive (45 years old religious leader). From FGD 1, for me, traditional birth attendants are mothers of pregnant and non-pregnant women because they are the decision-maker of the women regarding pregnancy plan, complication readiness, and preparedness but currently they reduce their help because of opposition in the local area. This is similar to the study conducted in a different part of African countries ${ }^{3,5}$

\section{Sub-theme 1.2 Assist labor and delivery}

About 5 women and 6 men in FGD 2 explain that traditional birth attendants like health professionals in assisting and delivery of the fetus, especially in remote areas. But some women may try without the skill they have, finally, the women and the child may die, so better give training for traditional birth attendants women. From the in-depth interview of TBA, most traditional birth attendants describe that we take care of the women when labor started as an emergency at home and on streets in the absence of nearby health facilities and health professionals. My wife is a traditional birth attendance with work experience of 10 years but she stops helping the women 5 years back because of punishment by the local judge. my wife assists the delivery of fetus during labor and delivery of the women without fee in charge and training. After my wife stops to help the women during labor, one mother died due to labor and delivery at home (39, 32, and 29 years old men). The other man said I am very interested my wife gets training on maternal and fetal care as well how to work with the health profession by being as a medium between the women and the health institutions (41 years old man). From my understanding Traditional birth attendance is my wife's mother because TBA always in the side of the mother when they are pregnant, labor and delivery as well in the post-partum period, so better to give training to the TBA rather than demotivated and punished them (the description of 37 and 56 years old men). this finding is consistent with the study done in Arba Minch. Explained as the pregnant women is still in the side of the traditional birth attendants and most women prefer home delivery with help of TBA due lack of transportation, lack of respect full care at health facility and long-distance to health facilities ${ }^{3,9}$

\section{Sub-theme 1.3 Care after delivery (Postnatal care)}

From the key informants, 45 and 60 years old religious leader clarifies that TBAs not only take care of the women during parturition but also they take care of the women in the post-partum period in form of cord 
care, placental removal and breastfeeding. Evidences from FGD 1 and 2 even if the TBAs helps the women in the post-partum period the advice about traditional milk teeth extraction and vulvectomy which

is a traditional practice, Which is in line with the reported of WHO by the year 2014 and other studies 3,8

\section{Sub-theme 1.4 Decision making for seeking care}

The women by default they are not the decision-maker in the house. Any decision in the house was made by the head of the house (by the husband). All the right of the women in the rural communities is on the hand of the husbands. In this case, the traditional birth attendants play a great role in helping the women to decide and prepare for delivery in a health facility as well TBAs condemned the force full and rigid ideas of the husbands (explanation of 39 and 67 years old community leaders) This is congruent with other studies as stated as the women decision making is on the hand of the husband and TBA as well the community health development armies ${ }^{9,13}$

\section{Sub-theme 1.5 Discontinuous the role they have}

Traditional birth attendance in the previous time they play an important role in our communities during pregnancy, childbirth, and post-partum period however, the major role is mainly during childbirth (explained by 40 years old community leader) and another community leader describe that currently, the traditional birth attendances are not working even if the women are in labor in the community, this is due to fear of penalty by a judge in nearby areas and total prohibiting by the government. Why TBA is punished for the reason of help women during pregnancy, childbirth, and after delivery? I strongly blame this phenomenon (35 years old community leader). In our village, all TBA is refusing to assist the laboring women because of prohibited by the lay in the local but remote areas of the country the role of TBA is very inspiring in all activities during pregnancy, labor, and postnatal period, so, please... Do not discourage them when they help the women rather prepare different training opportunities and improve the skill of TBA together with health extension workers to maximize the health of the women and child at the community level (described by more than $75 \%$ of the FGD members). Even if the role and practice of TBA, traditional health healer, we all Africans have a negative attitude towards the traditional healer, TBA, and other endogenous knowledge. Traditional birth attendances are sisters and mothers of pregnant women. They advise about pregnancy, labor and delivery process, post-partum care, and placental removal. Currently, in the remote area, the women delivered without an assistant at home and in the street, this is due to ignorant and punishment of the TBA by the local judge (the narration of 46 and 39 years old women). I personally happy when the TBA is in nearby when I was in labor, please, please.....do not prohibit them(37 years old woman) this supported by the study done at the country level 7,9

\section{Main theme 2 the integration of TBA with health facilities}




\section{Sub-theme 2.1 Formal relationship}

As per my experience, there is no relationship with TBA in the previous years. Because the government does not interlink the TBA with the health facility by giving training in advance but we integrate with health extension workers (narrated by 32 years old midwife) another midwife added that in some areas of Ethiopia there was a training of TBA and establishment of the formal relationship but it is not well done in all area of the country (the idea of 23, 45 and 30 years old midwives). This is supported by a study done in rural and urban areas of six partner countries in Asia and African countries, particularly in Ethiopia and Indonesia. This the slogan of African countries to decrease the feto-maternal mortality and morbidity by formally integrated the community midwives, health extension worker with the health facilities because a pregnant women's more likely trust the traditional birth attendants science they get service in privacy and safe area than the health facilities ${ }^{3} 5$

\section{Sub-theme 2.2 Informal relationship}

A few TBAs have come with the laboring women as a caregiver without exposing them as TBA, on the other hand, some TBAs come along with the women to health facilities to remove the placenta by attending a delivery of a fetus in the street however there is no formal letter communication with TBAs (the explanation of 24 and 40 years old midwives). As TBA I afraid to communicate with health professions because there is no established way to encourage us to work with the health facilities( description of 42 years old TBA). This is positively supported by the finding in Arba Minch and report of $\mathrm{WHO}^{3,13}$

\section{Sub-theme 2.3 Experience of TBA with health professions}

I appreciate the duties of some of the TBA, without any training they counsel the women to give birth at the health facility and bring the home delivery women to the health facility by helping the women in different health dimensions as well they try to deliver the women in a difficult situation like in remote areas in the absence of transportation and accidental delivery during transportation. The problem is the health policy of our country and the intention of the ministry of health towards TBA, that is negative attitude regarding (skills, experience, roles, and duty) of TBA (32 and 23 years old male and female degree midwife respectively).one midwife explain that as my understanding we should improve our endogenous skills of TBA to decease the Fetomaternal morbidity and mortality because the TTBA will smartly integrate the health facilities. In different African country and even the developed countries use trained traditional birth attendance to decrease maternal mortality ( 31 years old male midwife). This evidence is supported by done in Amara region 7,8 .

\section{Sub-theme 2.4 Training of TBA}


We all are on the side of TBA because they are the nearby mother to pregnant women more than the health extension workers and other health workers in health facilities. The service of TBA is countless and continuous throughout pregnancy, childbirth, and postnatal period but even if we trust them few TBA practices are inappropriate and dangerous to the women, so these TBA should be trained by trained health experts(explained by 34,45,23 men and 32,35,26 38 women). I observe that Traditional birth attendances are always with the women in day-to-day activities as a pass from generation to generation but now a day this is punishable together with the delivered women. For me, this is not the right way, because TBA helps the women more than the health professionals' special in high reach areas of Ethiopia rather better to train the TBA in all care of the women (the description of 56 and 68 years old religious leader. This is supported by the finding in Ormia and Amara Region. In this study the development and integration of community health development army, health extension worker and traditional birth attendance for team spirit in taking care of the women ${ }^{8}$

\section{Conclusion}

Locally demotivation and punishment of the TBA, lack of formal relationship between TBAs and the health facility resulted in increasing Feto-maternal morbidity and mortality especially in remote areas of the country. Even if the traditional birth attendants always on the side of the women in the previous year currently they forced to reduce their activity because of prohibited by a local judge and no motivation and training to improve the performance of TBA to trained traditional birth attendance. As a recommendation the ministry of health better works hard for the development of TBAs to TTBA like other African countries as well better to adapted the WHO recommendation 2014 for the scale-up of the skill of traditional birth attendance to trained traditional birth attendance in all countries as a whole.

\section{Abbreviations}

TBA Traditional Birth Attendance

TTBA Trained Traditional Birth Attendance

WHO World Health Organization

EMoH Ethiopian Ministry of Health

SNNPR South Nation Nationality and People Region

\section{Declarations}

\section{Ethical Approval letter}

The ethical approval letter is gathered from Midwifery Department on behalf of Mizan Tepi University and submitted to the West Omo Zone administration to get permission on different study set up in the 
zone. All the participants were informed about the purpose of the study before the period of data collection. Verbal consent was obtained from the participants during the data collection process. The participants' identification information was anonymous and based on the declaration of Helsinki.

\section{Publication consent}

Not relevant to this study

\section{Data availability}

The data is available on complaint authors based on the necessary request

\section{Competing of interest}

No competing interest

\section{Funding}

No fund is received

\section{Authors Contribution}

All authors were involved in the conception designing, analysis, and interpretation of the data. All the authors revise and check via the whole document. Finally, we approved to be published in a scientific journal.

\section{Acknowledgment}

First and most our heartfelt goes to Mizan Tepi University College of health science forgive this golden opportunity to exercise our effort to this research work. For next our thanks go to our colleagues in the department of midwifery for their uninterrupted support and suggestion. Finally, we thank the data collectors and the participants.

\section{References}

1. Lydia Aziato, and Cephas N. Omenyo, 'Initiation of Traditional Birth Attendants and Their Traditional and Spiritual Practices During Pregnancy and Childbirth in Ghana', BMC Pregnancy and Childbirth, 18 (2018), 64. 
2. Abbey Byrne, and Alison Morgan, 'How the Integration of Traditional Birth Attendants with Formal Health Systems Can Increase Skilled Birth Attendance', International journal of gynecology and obstetrics: the official organ of the International Federation of Gynaecology and Obstetrics, 115 (2011), 127-34.

3. M. Gurara, K. Muyldermans, Y. Jacquemyn, J. P. Van Geertruyden, and V. Draulans, 'Traditional Birth Attendants' Roles and Homebirth Choices in Ethiopia: A Qualitative Study', Women Birth, 33 (2020), e464-e72.

4. Zelee Hill, Yared Amare, Pauline Scheelbeek, and Joanna Schellenberg, '\&Lt;Em\&Gt;'\&Lt;/Em\&Gt; People Have Started to Deliver in the Facility this Days\&Lt;Em\&Gt;'\&Lt;/Em\&Gt;: A Qualitative Exploration of Factors Affecting Facility Delivery in Ethiopia', BMJ Open, 9 (2019), e025516.

5. Sudirman Nasir, Aschenaki Zerihun Kea, Rosalind Steege, Ralalicia Limato, Patricia Tumbelaka, Daniel Gemechu Datiko, Syafruddin, Maryse Kok, Rukhsana Ahmed, and Miriam Taegtmeyer, 'Cultural Norms Create a Preference for Traditional Birth Attendants and Hinder Health Facility-Based Childbirth in Indonesia and Ethiopia: A Qualitative Inter-Country Study', International Journal of Health Promotion and Education, 58 (2020), 109-23.

6. Roinah N. Ngunyulu, Fhumulani M. Mulaudzi, and Mmampheko D. Peu, 'Traditional Birth Attendants' Experiences During the Provision of Post-Natal Care in Mopani District, Limpopo Province of South Africa', Health SA = SA Gesondheid, 25 (2020), 1468-68.

7. Solomon Shiferaw, Mark Spigt, Merijn Godefrooij, Yilma Melkamu, and Michael Tekie, 'Why Do Women Prefer Home Births in Ethiopia?', BMC Pregnancy and Childbirth, 13 (2013), 5.

8. L. M. Sibley, S. Tesfaye, B. Fekadu Desta, A. Hailemichael Frew, A. Kebede, H. Mohammed, K. EthierStover, M. Dynes, D. Barry, K. Hepburn, and A. G. Gobezayehu, 'Improving Maternal and Newborn Health Care Delivery in Rural Amhara and Oromiya Regions of Ethiopia through the Maternal and Newborn Health in Ethiopia Partnership', J Midwifery Women's Health, 59 Suppl 1 (2014), S6-S20.

9. Tedla Mulatu Temesgen, Jemal Yousuf Umer, Dawit Seyoum Buda, and Tilahun Nigatu Haregu, 'Contribution of Traditional Birth Attendants to the Formal Health System in Ethiopia: The Case of Afar Region', The Pan African medical journal, 13 Suppl 1 (2012), 15-15.

10. H. Velimirovic, and B. Velimirovic, 'The Role of Traditional Birth Attendants in Health Services', Curare, 1 (1978), 85-96.

11. WHO, 'Improving Skilled Birth Attendance in Ethiopia', (2014).

12. World Health Statistics ', (2015).

13. world health organization, 'Improving Skilled Birth Attendance in Ethiopia', (2014).

\section{Figures}




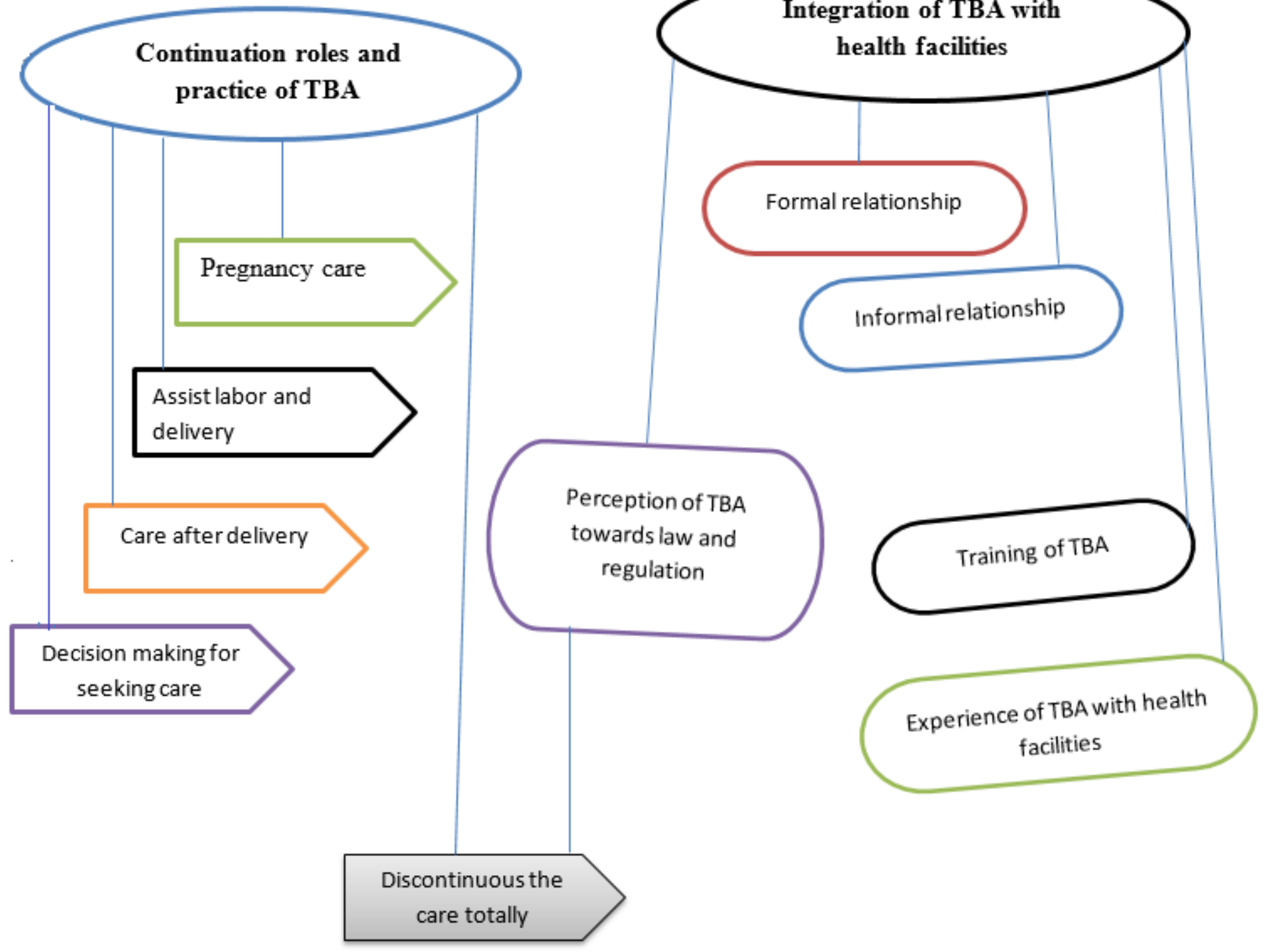

Figure 1

Thematic map on traditional birth attendance regarding the care and integration with health facilities in West Omo one, 2021 